\title{
Nancy Worth and Irene Hardill (eds.) (2015). Researching the Lifecourse. Critical Reflections from the Social Sciences. Bristol: Policy Press, 254 pp. ISBN 9781447317524 (hardcover)
}

\author{
ReVieWed by Carmen García NAVARRO*
}

Originated from a series of lectures given at the Association of American Geographers Meeting in New York in 2012, this book was published in 2015. The studies gathered here take the lifecourse concept as a research methodology. Building on Law's proposals to keep a debate on how research methods can capture social life (2004), the editors, Nancy Worth and Irene Hardill, highlight the importance of social science research in understanding that age is not the only variable involved in the lifecourse, but that lifecourse also implies individual and collective trajectories where experiences take place in time and space (Giele \& Elder 1998). Spaces and places are part of the environment of people's lives and determine their trajectory, as with notions and perceptions that people have of these experiences.

Theoretical contributions in this book are well balanced with practical developments. This is partly due to the breadth of the discussion and the outstanding academic rigour. The latter is apparent in both its content and approach, and in the specialist language used, which is malleable enough to be accessible to non-scholars interested in the subject. The value of this 
International Journal of Ageing and Later Life

collection lies in that it looks at the lifecourse from the perspectives of age, generation and inter-generation (generation), while also relying on the notions of transition/transit and life trajectories (transition). The relational aspects of age coexist in these studies with the concept of generation as a means of placing people both in time and in relation to each other, imbricated as they are in the notions of transits and trajectories. These are used to consider the changes that people experience throughout life. Thus, age and employment guide and determine the perceptions that individuals have about their lives. At the same time, especially in the Global North, age serves to structure the lifecourse into phases, such as childhood or youth, and their relation to work or migrations. These earlier segments in the division of the lifecourse have been widely investigated in recent studies, more so than adulthood and the mature stages of life.

The book is structurally and thematically cohesive and is divided into three parts, with four chapters each. This structure is enhanced by the editors' detailed introduction, which includes a list of tables, figures and other documents that serve the research purpose of some of the chapters, and a detailed index. Each part of the book is structured around a variable. The first is time. In "Time and the lifecourse: perspectives from qualitative longitudinal research", Bren Neale deals with the different natures and parameters used to research the flows of and over time in people's biographies. Relying on pre-existing data, Rose Lindsay, Elizabeth Metcalfe and Rosalind Edwards discuss in "Time in mixed methods longitudinal research: working across written narratives and large scale panel survey data to investigate attitudes to volunteering" the analytical and methodological challenges of a UK qualitative and quantitative study conducted with volunteers between 1981 and 2012, a period marked by recession and social austerity policies. John Goodwin and Henrietta O'Connor, in turn, stress in their "A restudy of young workers from the 1960s: researching intersections of work and lifecourse in one locality over 50 years", the need to further study the complexity of the intersections between work, locality and lifecourse. This part concludes with the article "A method for collecting lifecourse data: assessing the utility of the lifegrid" by Ann Del Bianco, who advocates the use of the lifegrid, a versatile and useful instrument for discerning between historical and narrative truths. 
Part 2 of the book focuses on the variables of space and place. Bisola Falola's chapter, entitled "Life geohistories: examining formative experiences and geographies," reflects on life geohistories as a method to explore the way in which places have a specific meaning in the lifecourse of young people, and how they determine their beliefs and actions. The mapmaking method was used by Bree Akesson in his study "Using mapmaking to research the geographies of young children affected by political violence." This is a revealing instrument in exploring how children are sources of knowledge about themselves and their lives. Sophie Bowlby's chapter, "Keeping in touch: studying the personal communities of women in their fifties," states that it is essential to study communities of middle-aged women, "a neglected group" (p. 158), and the representation that these women make of their links with other members of their community through their lifecourse. In these links to their past, current and future experiences, the emotional component plays a key role when it comes to understanding and interpreting women's lives. The chapter by Kaisa Schmidt-Thomé, "Triangulation with softGIS in lifecourse research: situated action possibilities and embodied knowledge," discusses the potential of geobiographies as a method for shedding light on the material aspect of people's lives. The researcher uses this method to evoke the past in the present and find reverberations into the future, and sees it as a useful tool for researching learning and ageing processes.

Part 3 of the book deals with different forms of mobilities. In the chapter entitled "Using a life history approach within transnational ethnography: a case study of Korean New Zealander returnees," Jane Yeonjae Lee draws from autoethnography and transnational ethnography, relying on her personal experience as a migrant. Using the life stories technique, she shows the complexity and potential of her research on Korean migrants in New Zealand who returned to their country between 1999 and 2009. Anne Leonora Blaakilde focuses on the interaction and co-construction of knowledge between the researcher and the people in her chapter "Sensing sense and mobility at the end of the lifecourse: a methodology of embodied interaction," presenting a case-study on Nordic migrants in Turkey. In so doing, the researcher relies on the intersubjectivity of those who participate in the research process, above and beyond any ideal of objectivity. Francoise Dureau, Matthieu Giroud and Christopher Imbert study in 
International Journal of Ageing and Later Life

"Event history approach to life spaces in French-speaking research" how mobility in different European metropolitan areas affects the day-to-day individual behaviour in these spaces, and in the relationships of people with places and over time. Finally, Melissa Kelly advocates the need to further the theoretical and methodological studies of highly qualified migrants in "Using an intersectional lifecourse approach to understand the migration of the highly skilled." This chapter proposes that it is necessary to make intersectional and multimodal approaches based on social theory that can contribute additional nuances to the study of decisions about the reasons to emigrate. This is intended to gain a better understanding of the phenomenon, without ignoring migrants' subjectivity and agency.

The book is, above all, an interesting and convincing study as well as a carefully edited volume, covering aspects ranging from typography to the colour design of the front and back covers. Undoubtedly, this is a novel important contribution to lifecourse research in the social sciences, which encourages discussion and provides an update of recent progress in the area, while at the same time supporting and serving as a reference for new studies in the field.

\section{References}

Giele, J. Z. and Elder, G. H. (1998). Methods of life course research: Qualitative and quantitative approaches. Thousand Oaks, CA: Sage.

Law, J. (2004). After the method: Mess in social science research. Abingdon, Oxon: Routledge. 